\title{
Study on Mixture Ratio Design Method of AC-20C Modified Foamed Asphalt Mixture
}

\author{
KejiaLiu ${ }^{1, a}$, Bin Liang ${ }^{1, b}$ \\ Civil Engineering School, Henan University of Science and Technology, Luoyang 471023, China \\ a154966973@qq.com, bliangbin4231@163.com
}

Keywords: foam asphalt mixture; mixture ratio design; mixture ratio test

Abstract. The design process of mixture ratio of foamed asphalt mixture is studied in the paper. By means of a series of asphalt test, the best foaming condition, mineral aggregate gradation and the best ratio of asphalt is determined. The road performance test of foam asphalt mixture is carried out to verify the mixture ratio. The results show that the pavement performance of foam asphalt mixture can meet the specification requirements and can be put into practical application.

\section{Introduction}

The technology of warm mix asphalt foaming is to connect the asphalt foaming equipment with the traditional intermittent asphalt mixing station, Water and high pressure gas is injected into the asphalt foaming equipment to form a steam bubble. Foamed asphalt is formed by the combination of steam bubbles and hot asphalt in the asphalt conveying pipe. The viscosity of foamed asphalt is lower than that of common asphalt[1-2]. The foam asphalt mixture is formed under the condition that the heating temperature of the aggregate and asphalt is reduced by $20^{\circ} \mathrm{C}-30^{\circ} \mathrm{C}$.

The asphalt mixture construction production needs to carry on the mix proportion design first and carries on the mix proportion design verification[3]. Based on the DeShang expressway engineering, this paper research on the mixture proportion design of the foam asphalt mixture, and compares it with the hot mix SBS modified asphalt mixture with the same mixing ratio.

\section{Determine the optimum foaming conditions}

Raw material. 70-Aasphalt used in the test is produced by Shandong highway material storage and transportation company. The aggregates of different particle size of limestone and slag, produced in Shandong blue stone processing company. The material of each aggregate bin is screened and the density is measured. The measured value of aggregate density is shown in the Tab.1.

Tab.1 Aggregate density determination

\begin{tabular}{|c|c|c|c|c|c|c|}
\hline $\begin{array}{c}\text { Material } \\
\text { specifications }\end{array}$ & $5 \#(16-22 \mathrm{~mm})$ & $\begin{array}{c}4 \# \\
(11.2-16 \mathrm{~mm})\end{array}$ & $\begin{array}{c}3 \# \\
(6-11.2 \mathrm{~mm})\end{array}$ & $\begin{array}{c}2 \# \\
(3.5-6 \mathrm{~mm})\end{array}$ & $\begin{array}{c}1 \# \\
(0-3.5 \mathrm{~mm})\end{array}$ & powder \\
\hline $\begin{array}{c}\text { Apparent relative } \\
\text { density }\end{array}$ & 2.718 & 2.718 & 2.727 & 2.732 & 2.729 & 2.665 \\
\hline $\begin{array}{c}\text { Gross volume } \\
\text { relative density }\end{array}$ & 2.710 & 2.702 & 2.684 & 2.672 & 2.747 \\
\hline
\end{tabular}

Based on the two indexes of expansion rate and half-time in 《Technical specification for highway asphalt pavement regeneration》, the optimum asphalt heating temperature are selected under the conditions of $0.5 \%, 1 \%, 1.5 \%, 2 \%$ and the optimum foaming water quantity are selected under the conditions of $165^{\circ} \mathrm{C}$ and $175^{\circ} \mathrm{C}$. The results of expansion rate and half-time test are shown in Fig.1. 


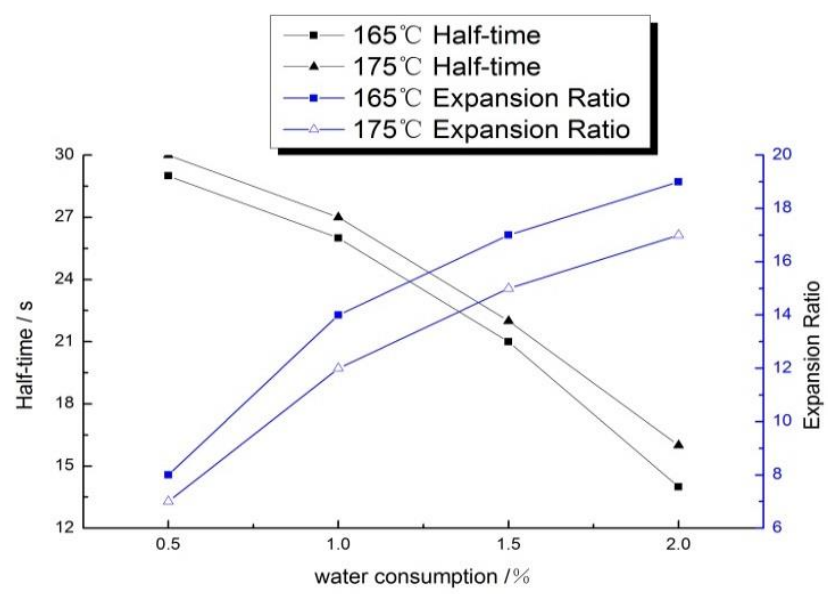

Fig.1 Expansion rate and half-time under different temperature and water consumption

The result shows that both the asphalt heating temperature of $165^{\circ} \mathrm{C}$ or $175^{\circ} \mathrm{C}$ when the foaming water is $1 \%$ and $1.5 \%$, while the half-time of foam asphalt and expansion rate can achieve better effect, and in the $1 \%$ foaming water content conditions two performance indexes are closer, and meet the requirements of the standard expansion rate not less than 10 times and the half-life of not less than $8 \mathrm{~s}[4]$. Therefore, the selection of lower asphalt heating temperature $165^{\circ} \mathrm{C}$, foaming water consumption of $1 \%$ of its best foaming conditions.

\section{Aggregate gradation design}

The method of man-machine conversation is used to optimize the synthetic gradation according to the results of aggregate screening. Make it as close as possible to the target gradation. The proportion of various materials: $5 \#: 4 \#: 3 \#: 2 \#: 1 \#$ powder=21: $18: 20: 14: 23.5: 3.5$. It is used for hot mix asphalt mixture and warm mix asphalt mixture at the same time. The calculated results are shown in Fig.2.

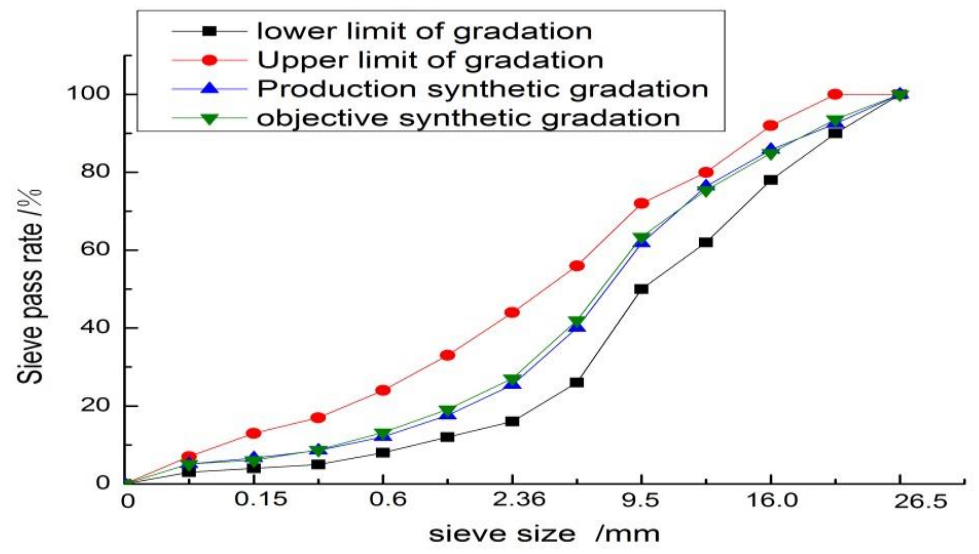

Fig.2 Gradation composition of asphalt mixture 


\section{Optimum asphalt aggregate ratio}

Using $4.3 \%, 4.6 \%$ and $4.9 \%$ asphalt content to make foam asphalt mixture. The test specimens were made, the physical indexes were measured, and Marshall test was carried out, The asphalt aggregate ratio with the gross volume relative density, air voids, VMA, saturation, stability and flow value relationship was measured. The relationship between asphalt aggregate ratio and the physical indexes is shown in Fig.3.
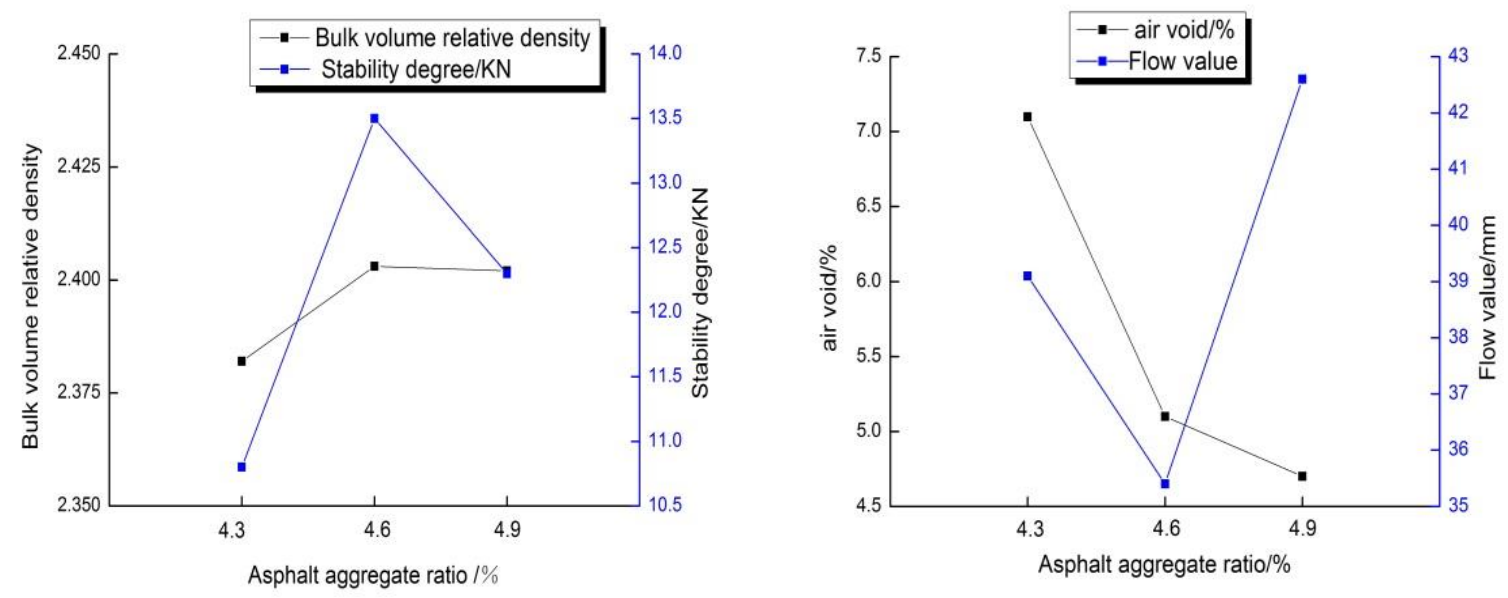

Fig.3 The relationship between asphalt aggregate ratio and the physical indexes

In the $4.6 \%$ aggregate ratio, the bulk volume relative density and stability of the mixture are higher, flow value and air void are lower. So $4.6 \%$ is the optimum asphalt aggregate ratio. The foam asphalt mixture bulk density is 2.403 , mixture porosity is $5.1 \%$, stability is $13.5 \mathrm{KN}$, the flow value is $3.54 \mathrm{~mm}$, saturation is $68.4 \%$, VMA is $14.2 \%$. These indicators all meet the specifications and design requirements. The mixture ratio are shown in the Tab.2.

Tab.2 Mixture ratio

\begin{tabular}{|c|c|c|c|c|c|c|c|}
\hline Material & $\begin{array}{c}\text { foam } \\
\text { asphalt }\end{array}$ & $5 \#(16-22 \mathrm{~mm})$ & $4 \#(11.2-16 \mathrm{~mm})$ & $3 \#(6-11.2 \mathrm{~mm})$ & $2 \#(3.5-6 \mathrm{~mm})$ & $1 \#(0-3.5 \mathrm{~mm})$ & Powder \\
\hline Ratio $(\%)$ & 4.6 & 21 & 18 & 20 & 14 & 23.5 & 3.5 \\
\hline
\end{tabular}

\section{Mixture ratio test}

In the design of asphalt pavement, asphalt aggregate ratio and void ratio is the main index of concern. In the premise of gradation is determined, and the void ratio and the asphalt aggregate ratio has a direct relationship. Big stone, it will appear high temperature rutting, flushing and other diseases. Less stone, the fatigue resistance of the pavement is not guaranteed and easy to produce water damage. Therefore the optimum asphalt aggregate ratio determined in the asphalt mixture design is particularly important.

The mixture specimens were subjected to high temperature and low temperature performance test. Rutting test is commonly used to evaluate the high temperature stability of asphalt mixture. $300 \times 300 \times 50 \mathrm{~mm}$ standard rut plate specimen was made by wheel mill. The three pieces of each group were placed in the automatic rut tester for maintenance after $7 \sim 9 \mathrm{~h}$, then measure its dynamic stability. Evaluation the low temperature cracking resistance of asphalt mixture by small beam bending test. The results of rutting test and bending test are shown in Fig.4 and Fig.5. 


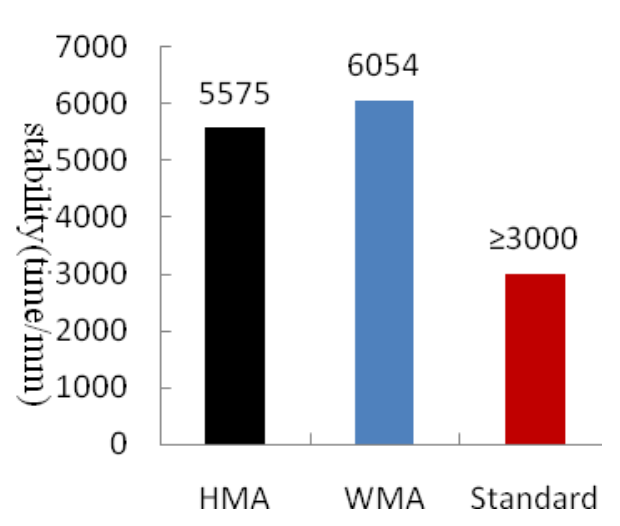

Fig.4 Results of rutting test

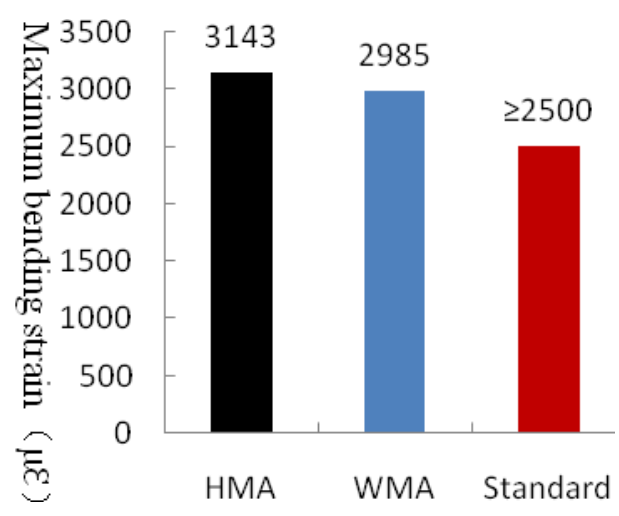

Fig.5 Bending test at low temperature

The dynamic stability of foamed asphalt mixture is $6054 / \mathrm{mm}$, which is higher than that of hot mix asphalt mixture. Compared with hot mix asphalt mixture, the dynamic stability of the foam asphalt mixture has 7\% increase, showing a better high-temperature rutting resistance. The maximum flexural strain of foamed asphalt mixture is slightly lower than that of hot mix asphalt mixture, but it is far more than $2500 \mu \mathcal{E}$ of the standard requirements.

\section{Conclusion}

Ultimately it is determined that the production of foamed asphalt in asphalt heating temperature of $165^{\circ} \mathrm{C}$ and foaming with $1 \%$ water is the optimum foaming condition of asphalt. The optimum asphalt aggregate ratio is $4.6 \%$. The volume index and mechanical index of foam asphalt mixture can meet the requirements of specification. The performance of foamed asphalt mixture completely meets the design requirements of the standard.

\section{References}

[1] F.Z. Shi, D.Q. Sun, Laboratory Research on Physical and Mechanical Characteristics of Foamed Bitumen Mixtures, J, Highway. 2(2004)142-144. (In Chinese)

[2] X.J. Li, F.Z. Shi, Influence of Water Percentage on Performance of Foamed Bitumen Mixture, J, Journal of building materials. 1(2008)65-67. (In Chinese)

[3] J.Y. Xiong, Study on Design Method and Road Performance of Foam Asphalt Warm Asphalt Mixture, J, Highway Engineering. 5(2016)128-130. (In Chinese)

[4] F. Wang, L.H. Li, Experimental Research on Some Problems in Mixture Design of Warm Mix Asphalt, J, Journal of East China Jiaotong University. 4(2010)22-25. (In Chinese) 